\title{
De evaluatie van biofysica als pilotproject voor blended learning
}

\author{
J. Beullens · J. Rogiers $・$ L. Volkaert $\cdot$ E. Struyf
}

Samenvatting Inleiding: Blended learning streeft een integratie na van een elektronische met een fysieke leeromgeving. Hoewel dit in het medisch onderwijs vaak wordt toegepast, werd blended learning zelden geëvalueerd. Als pilotproject werd het opleidingsonderdeel biofysica uit de eerste bachelor geneeskunde en tandheelkunde in 2004-2005 in die zin aangepast. In dit onderzoek werd nagegaan hoe deze onderwijsvernieuwing werd ervaren door studenten en docent, en wat het effect was op de examenuitslagen van de drie vakken die in hetzelfde semester geëxamineerd werden.

Methode: Na elk van de drie oefeningentoetsen vulden de studenten een vragenlijst in bestaande uit 19 items en na het eindexamen een vragenlijst met 32 meer verfijnde vragen. Alle items zijn geformuleerd als beweringen, waarbij de studenten op een zespuntenschaal de mate aangeven dat ze ermee akkoord gaan. Van de docent werd een interview afgenomen. De examenuitslagen van de drie vakken werden vergeleken met deze van de voorgaande drie jaren.

Resultaten: Meer dan 80\% van de 304 studenten werkten mee aan de evaluaties na de oefeningentoetsen en aan de eindevaluatie. De globale indruk van zowel studenten als docent was positief en betrof de meeste aspecten van de nieuwe onderwijsaanpak. De vergelijking van de examenuitslagen van de vier jaren binnen

\footnotetext{
J. Beullens $(\square)$

Drs. J. Beullens is psycholoog en wetenschappelijk medewerker aan de Dienst Onderwijs Geneeskunde, Faculteit

Geneeskunde, Katholieke Universiteit Leuven. Correspondentieadres:Drs. Johan Beullens, Dienst Onderwijs Geneeskunde, Faculteit Geneeskunde, K.U. Leuven, Onderwijs en Navorsing 2, Herestraat 49 bus 400, B-3000 Leuven, België, Johan.Beullens@med.kuleuven.ac.be. Belangenconflict: geen gemeld.Financiële ondersteuning: geen gemeld.
}

een vak was alleen significant voor biofysica. De gemiddelde uitslag in het laatste jaar was daarbij significant hoger dan deze in elk van de drie voorgaande jaren.

Discussie en conclusie: De integratie van de elektronische met de fysieke leeromgeving werd gunstig onthaald door studenten en docent, en resulteerde in een betere examenuitslag. (Beullens J, Rogiers J, Volkaert L, Struyf E. De evaluatie van biofysica als pilotproject voor blended learning. Tijdschrift voor Medisch Onderwijs 2007;26(2):82-90.)

\section{Inleiding}

Een elektronisch leerplatform wordt vaak inefficiënt gebruikt, omdat de informatie en hulpmiddelen die erop aangeboden worden te los van het contactonderwijs staan en daardoor vaak door de studenten ten onrechte als 'extra' worden aangezien. ${ }^{1}$ Blended learning streeft een integratie na van een elektronische met een fysieke leeromgeving. Harden en Hart spreken over een geschikt mengsel van e-learning en traditionele face-to-face learning. ${ }^{2}$ Een PubMed-search naar 'blended learning' in 'medical education' levert amper tien referenties op. In de meeste van deze tijdschriftartikelen komt blended learning slechts zijdelings aan bod. Drie artikelen betreffen de evaluatie van de introductie van een gemengde leeromgeving. Bij Shaffer en Small ging het om het opleidingsonderdeel radiologische anatomie bij eerstejaarsstudenten en was de evaluatie beperkt tot een tevredenheidsvragenlijst. ${ }^{3}$ Een soortgelijke vragenlijst breidden Taradi en medewerkers uit met examenscores om de evaluatie in kaart te brengen van het opleidingsonderdeel fysiologie in het tweede jaar geneeskunde. ${ }^{4}$ 
Gordon en coauteurs evalueerden een training rond beroerte bij paramedici aan de hand van toetsen met meerkeuzevragen en twee gesprekken met gestandaardiseerde patiënten. ${ }^{5}$ De doeltreffendheid van een doordachte combinatie van een elektronische met een fysieke leeromgeving in het medisch onderwijs werd tot op heden dus zelden onderzocht.

Als pilotproject in de Faculteit Geneeskunde in Leuven werd in 2004-2005 het opleidings-onderdeel biofysica uit het eerste bachelorjaar geneeskunde en tandheelkunde in die zin herwerkt. Deze hervorming houdt een uitbreiding in van de zelfwerkzaamheid van de studenten zonder dat de studiebelasting toeneemt; onder meer door het aantal contacturen te beperken.

Vroeger omvatte dit opleidingsonderdeel vier uur hoorcollege per week, drie uur oefeningensessies per week en acht uur practica per semester, tijdens dewelke fysische wetmatigheden werden geïllustreerd. Problemen daarbij waren dat de studenten hun studeren uitstelden en onvoorbereid naar de oefeningensessies kwamen. Dit is des te problematischer, omdat de leerinhoud steeds op zichzelf voortbouwt. Dit resulteerde in frustraties, zowel bij de studenten als bij de assistenten die hen begeleiden tijdens de oefeningensessies.

In het nieuwe concept begint de week met een introductiecollege op maandag, waarin theorie en toepassingen in grote lijnen worden ingeleid. Aansluitend worden eenvoudige oefeningen en toepassingen, die de studenten alleen moeten oplossen, als taak op het elektronische leerplatform geplaatst. Als hierbij problemen opduiken, kunnen de studenten deze aan elkaar voorleggen op het discussieforum. Ze dienen daarbij het probleem duidelijk te formuleren en zelf een aanzet tot antwoord te geven. Het zijn in eerste instantie de medestudenten die de vraagsteller trachten verder te helpen. De docent bekijkt eens per week wat op het discussieforum staat en intervenieert alleen wanneer dat nodig is (b.v. indien een verkeerd spoor te lang wordt gevolgd). Tijdens de oefeningensessies op donderdag worden deze taken opgelost en worden in de groep moeilijkere oefeningen aangepakt. Aan de hand van de problemen die opdoken tijdens de oefeningensessie en de vragen die studenten stelden op het forum, bepaalt de docent op welke onderdelen dieper zal ingegaan worden tijdens het synthesecollege op vrijdag. Tijdens dit college komen ook verdere toepassingen aan bod. Het elektronische leerplatform dient om het studieplan en de taken aan te bieden, het discussieforum open te stellen en te beheren, en oplossingen van oefeningen, toetsen en examenvoorbeeldvragen te presenteren.

Tijdens het semester werden vier thema's behandeld. $\mathrm{Na}$ de eerste drie werd telkens een oefeningentoets afgenomen en had een evaluatie van de vernieuwing plaats door de studenten. De oefeningentoets had zowel een summatieve als een formatieve functie: ze kon meetellen, maar na afloop werden de oplossingen wel besproken, zodat de studenten er wat van opstaken. De drie evaluaties door de studenten in de loop van het semester dienden om het proces in kaart te brengen, zodat dit desgewenst kon bijgestuurd worden. $\mathrm{Na}$ het vierde thema kwam het eindexamen, gevolgd door een eindevaluatie van het project. De twee beste scores op de drie oefeningentoetsen konden meetellen voor 4 van de 20 examenpunten en 1 punt werd toegekend aan de uitvoering van de taken. Vlak voor het examen besliste de student echter of de toetsen meetelden; indien niet, dan kreeg deze student extra oefeningen tijdens het examen waarop eveneens 4 punten stonden.

De introductie van deze onderwijsinnovatie was niet zonder risico. Enerzijds was het mogelijk dat de studenten niet instapten in de nieuwe werkwijze en doordat de inhoud voortbouwt, zou dit waarschijnlijk neerkomen op vroegtijdig afhaken. Anderzijds was het mogelijk dat ze zoveel tijd gingen investeren in biofysica dat de twee andere opleidingsonderdelen die eveneens in het eerste semester geëxamineerd werden - met name algemene en biologische scheikunde en vergelijkende biologie - er onder leden. In deze publicatie wordt gerapporteerd over de evaluatie van dit pilotproject. De drie onderzoeksvragen zijn:

1. Welke aspecten worden het meest geapprecieerd door de studenten en welke wensen zij bijgeschaafd te zien?

2. Welke aspecten worden het meest geapprecieerd door de docent en welke wenst hij te veranderen?

3. Wat is het effect op de examenuitslagen van de drie vakken die in hetzelfde semester geëxamineerd werden?

\section{Methode}

Studenten

Het opleidingsonderdeel biofysica wordt gelijktijdig gedoceerd aan studenten geneeskunde en tandheelkunde. De 304 studenten uit het eerste bachelorjaar die dit opleidingsonderdeel voor het eerst kregen, vormden de doelgroep; zittenblijvers werden niet verwacht aanwezig te zijn.

Vragenlijsten

$\mathrm{Na}$ elk van de drie oefeningentoetsen vulden de studenten een vragenlijst in bestaande uit 19 beweringen, waarvan de studenten aangaven in welke mate ze het daarmee eens waren op een zespuntenschaal van 1 (helemaal niet 
akkoord) tot 6 (helemaal akkoord). Alle aspecten van de nieuwe aanpak komen daarin aan bod: introductiecollege ( 3 items), discussieforum ( 3 items), oefeningensessies ( 3 items), synthesecollege ( 2 items), tussentijdse toets en voorbereiding op het examen (4 items) en studiebelasting en monitoraat (3 items). De vragenlijst eindigt met een item dat de algemene tevredenheid over de gekozen onderwijsformule betreft. Bij de analyse werd bij negatief geformuleerde beweringen de puntenwaardering invers toegepast vooraleer het gemiddelde te berekenen.

$\mathrm{Na}$ het eindexamen volgde een vragenlijst met 3 kortantwoordvragen en 32 beweringen, eveneens te beoordelen op een zespuntenschaal. In deze vragenlijst komen nieuwe aspecten aan bod (elektronisch leerplatform en examen) en zijn meer verfijnde vragen opgenomen over reeds bevraagde aspecten. De onderdelen zijn: introductiecollege (6 items), elektronisch leerplatform (2 items), discussieforum (3 items), oefeningensessies (3 items), monitoraat (3 items), synthesecollege (3 items), toetsen (4 items), studiebelasting (4 items), voorbereiding op het examen ( 3 items), examen ( 3 items), en het globaal item over de onderwijsaanpak. De punten werden omgekeerd bij negatief geformuleerde beweringen vooraleer het gemiddelde werd berekend. Van de docent werd een interview afgenomen. Zijn uitspraken werden letterlijk genoteerd.

De examenuitslagen van de drie vakken in 2004-2005 werden vergeleken met deze van de voorgaande drie jaren. Bij de vergelijking van de vier jaren binnen een vak werd de ANOVA gebruikt en - indien significant de t-toets bij de paarsgewijze vergelijking van de jaren.

\section{Resultaten}

De respons bedroeg na de drie oefeningentoetsen respectievelijk $87 \%, 88 \%$ en $83 \%$ en bij de eindevaluatie $82 \%$. De studenten waren na de toetsen eerder tevreden over de nieuwe onderwijsaanpak met een score tussen 4 en 4.5 op de zespuntsschaal (zie tabel 1). De aspecten die het meest positief werden beoordeeld (alle gemiddelden boven 4) waren: de taken gegeven tijdens het introductie-college waren uitdagend, er was voldoende tijd beschikbaar om deze uit te voeren, het feit dat ze punten konden verdienen met toetsen en taken, en de afstemming van oefeningensessies en theorie op elkaar. Minst gunstig beoordeeld werden (één of meerdere gemiddelden onder 3.5): het plaatsen van vragen op het discussieforum, de beantwoording tijdens het synthesecollege van vragen gesteld via het discussieforum, de feedback tijdens het synthesecollege op de uitvoering van opdrachten, de beschikbaarheid van de monitor, en de tijd die rest voor de studie van de twee andere vakken.
Het reeds gunstige algemene oordeel na de toetsen (een score tussen 4 en 4.5) was nog positiever na het eindexamen met een score van ongeveer 5 . Ongeveer dezelfde aspecten als bij de tussentijdse evaluatie werden positief beoordeeld (gemiddelden boven 4.5 of - bij negatief geformuleerde vragen - onder 2.5): de taken waren een goede voorbereiding op de oefeningensessie, en de toekenning van punten aan toetsen en taken (zie tabel 2). Door de nieuwe vragen in de lijst blijkt verder ook (gemiddelden boven 4.5 of - bij negatief geformuleerde vragen - onder 2.5): de studenten hebben de taken zelf uitgevoerd, het elektronisch leerplatform was een hulp, het posten van vragen op het discussieforum werd niet vermeden omwille van te typen symbolen, de beslissing lag bij de student of de oefeningentoetsen meetellen, het proefexamen over de theorie moet blijven bestaan, de informatie over het examen was correct en er was voldoende tijd om het examen af te leggen.

De rapportering over het interview afgenomen van de docent wordt beperkt tot een samenvatting. De globale indruk van de docent is erg positief en de meeste aspecten van de nieuwe onderwijsaanpak wenst hij te behouden. De studenten zijn tijdig begonnen met werken aan biofysica. De oefeningensessies verliepen veel vlotter dan de voorgaande jaren. De overbelasting van het monitoraat op het einde van het semester is verminderd. En last but not least: de uitslagen waren beter, terwijl de inhoud van het examen niet veranderd was.

Wel was dit eerste jaar, waarin alles moest ontwikkeld worden, de belasting voor de docent erg groot. Vooral het klaarmaken van alle informatie heeft veel tijd gevergd. Het bijhouden van de informatie op het discussieforum zou minder tijd vereisen, indien dit gebruiksvriendelijker was. Enkele elementen van de aanpak zullen bijgeschaafd worden. De introductiecolleges moeten minder gedetailleerd worden en de synthesecolleges moeten meer feedback op de oefeningen bevatten. De hoofdstukken uit de cursus, die momenteel herschreven wordt, zullen beter overeenkomen met de vier grote themablokken. De dia's van de presentaties tijdens de colleges zullen reeds in het begin van het semester beschikbaar zijn in plaats van na de betreffende colleges en ze zullen zo uitgewerkt worden dat de studenten ze tijdens de colleges kunnen aanvullen.

Op het einde van het eerste semester legden de studenten examen af voor biofysica, algemene en biologische scheikunde en vergelijkende biologie. De gemiddelde uitslag op biofysica was sterk gestegen met 1.7 punten op 20 (zie figuur 1) en het aantal onvoldoendes sterk gedaald van 45 naar 15 (zie figuur 2). Bij vergelijking van de examenuitslagen van de vier jaren binnen één vak was de ANOVA alleen significant voor biofysica. Uit de ttoetsen bleek dat de gemiddelde uitslag in het laatste jaar 
Tabel 1 Mate waarin de studenten het eens zijn met de beweringen (gemiddelden van de drie tussentijdse evaluaties*).

\begin{tabular}{|c|c|c|c|c|}
\hline & Item & $\begin{array}{c}\text { Eval } \\
1 .\end{array}$ & $\begin{array}{r}\text { Eval. } \\
2\end{array}$ & $\begin{array}{r}\text { Eval } \\
.3\end{array}$ \\
\hline \multirow[t]{2}{*}{1.} & In het introductiecollege bij het begin van elk thema werden theorie en & & & \\
\hline & toepassingen in grote lijnen geschetst & 3.97 & 3.95 & 4.08 \\
\hline 2. & Ik kreeg voldoende tijd om de opdrachten en taken uit te werken tegen de afgesproken datum & 4.70 & 4.53 & 4.50 \\
\hline 3. & De opdrachten gegeven tijdens het introductiecollege waren voldoende uitdagend & 4.50 & 4.37 & 4.15 \\
\hline 4. & Ik heb gebruik gemaakt van het discussieforum om vragen te stellen & 2.26 & 2.56 & 2.83 \\
\hline 5. & Ik heb op het discussieforum geplaatste informatie gelezen & 3.90 & 4.21 & 4.14 \\
\hline 6. & Ik vond de vragen en antwoorden op het discussieforum relevant bij het studeren & 3.73 & 4.10 & 4.06 \\
\hline 7. & De oefeningen die ik moest uitvoeren tijdens de oefeningensessies waren te moeilijk & 2.83 & 3.20 & 2.99 \\
\hline 8. & $\begin{array}{r}\text { Bij het oplossen van de oefeningen tijdens de oefeningensessies werden wij door de assistenten goed } \\
\text { begeleid }\end{array}$ & 4.04 & 3.99 & 4.10 \\
\hline 9. & De oefeningensessies waren goed afgestemd op de theorie & 4.62 & 4.45 & 4.26 \\
\hline 10. & $\begin{array}{r}\text { Tijdens het synthesecollege gaf de docent voldoende informatie in antwoord op vragen gesteld door } \\
\text { studenten via het discussieforum }\end{array}$ & 3.61 & 3.68 & 3.22 \\
\hline 11. & $\begin{array}{r}\text { Tijdens het synthesecollege gaf de docent naast de oplossing ook feedback i.v.m. de opdrachten en taken } \\
\text { die hij tijdens het introductiecollege had gegeven }\end{array}$ & 3.67 & 3.43 & 3.56 \\
\hline 12. & Ik was goed geïnformeerd over het soort vragen waaruit de toets zou bestaan & 4.12 & 3.86 & 4.19 \\
\hline 13. & $\begin{array}{r}\text { De oefeningen uitgevoerd tijdens de oefeningensessies en de opdrachten en taken ontvangen tijdens de } \\
\text { introductiecolleges hebben mij goed voorbereid op de toets }\end{array}$ & 4.38 & 4.06 & 4.19 \\
\hline \multirow[t]{2}{*}{14.} & Ik vind het goed dat er punten toegekend worden aan de toetsen en aan & & & \\
\hline & medewerking aan de taken & 4.25 & 4.32 & 4.60 \\
\hline 15. & Verdere vragen waar ik mee bleef zitten, heb ik aan de monitor kunnen stellen & 4.00 & 3.51 & 3.32 \\
\hline 16. & De studiebelasting voor biofysica was aanvaardbaar & 3.96 & 3.94 & 4.08 \\
\hline \multirow[t]{2}{*}{17.} & Door al dat werk voor biofysica restte er te weinig tijd voor studie van de & & & \\
\hline & andere opleidingsonderdelen & 4.06 & 3.65 & 3.47 \\
\hline \multirow[t]{2}{*}{18.} & Door deze combinatie van onderwijsleeractiviteiten voel ik mij goed & & & \\
\hline & voorbereid op het examen (op het einde van het semester) & 4.33 & 4.01 & 3.96 \\
\hline 19. & Ik ben tevreden over de gekozen onderwijsformule & 4.41 & 4.29 & 4.27 \\
\hline
\end{tabular}

daarbij significant hoger was dan deze in elk van de drie voorgaande jaren.

\section{Discussie}

$\mathrm{Na}$ de drie toetsen zijn de studenten eerder tevreden over de gekozen onderwijsformule. Zij staan ook eerder positief tegenover de meeste aspecten daarvan. Slechts enkele studenten plaatsen vragen op het discussieforum (item 4). Dit betekent echter geenszins dat dit niet gebruikt wordt. De studenten lezen wel de informatie op het discussieforum en vinden deze relevant bij het studeren (items 5 en 6). Uit de eindevaluatie blijkt verder dat het niet plaatsen van vragen niet te wijten is aan technische problemen door de aanwezigheid van symbolen. Er is blijkbaar een drempel voor het plaatsen van vragen op het forum.

Enkele van de tussentijdse oordelen worden gecorrigeerd bij de eindevaluatie. De studenten ontkennen eerder dat ze met hun vragen niet bij het monitoraat terecht konden, omdat dit reeds volzet was (item 15) en dat er te weinig tijd overbleef voor andere vakken (item 25) of voor ontspanning (item 26). In de loop van het semester is omgeschakeld van een individuele begeleiding door de monitor naar een begeleiding in kleine groepjes; mogelijk heeft deze verandering in werkwijze het oordeel doen kantelen. De studenten houden er een uitgesproken standpunt op na (gemiddelden boven 5) over de toetsen. Ze vinden het goed dat er punten toegekend worden, zowel aan de toetsen (item 21) als aan medewerking aan de taken (item 22). Ze vinden beide aspecten, die in de tussentijdse bevraging in één item zaten, dus even belangrijk. Nog belangrijker vinden ze dat de beslissingsmacht of de tussentijdse toetsen al of niet meetellen bij het examen bij henzelf ligt (item 23). Het item 'ik heb bij het examen voldoende tijd gekregen' krijgt ook een gemiddelde score boven 5 (item 34). Aangezien vele deelaspecten gunstig beoordeeld worden, is het geen wonder dat de studenten globaal tevreden zijn over de onderwijsaanpak (gemiddelde 4.92). Na het examen, wanneer het 
Tabel 2 Mate waarin de studenten het eens zijn met de beweringen (gemiddelde van de eindevaluaties*).

\begin{tabular}{|c|c|c|}
\hline & Item & Gem. \\
\hline 1. & Ik had voldoende voorkennis om biofysica te kunnen volgen & 4.44 \\
\hline 2. & Het introductiecollege hielp me om dezelfde leerstof in het boek te begrijpen & 4.13 \\
\hline 3. & Ik had het college beter kunnen volgen indien ik bij aanvang reeds over de slides beschikte & 3.89 \\
\hline 4. & Ik vond de taken een goede voorbereiding op de oefeningen tijdens de oefeningensessie & 4.72 \\
\hline 5. & Ik heb sommige van de opgelegde taken niet zelf uitgevoerd & 1.61 \\
\hline 6. & Ik heb het door de docent verstrekte studietraject (semesterplan) geraadpleegd & 3.81 \\
\hline 7. & Bij al mijn werk voor biofysica ervoer ik het elektronisch leerplatform als een hulp & 4.70 \\
\hline \multirow[t]{2}{*}{8.} & We werden er voldoende van op de hoogte gebracht wanneer nieuwe informatie op & \\
\hline & het elektronisch leerplatform verscheen & 4.29 \\
\hline 9. & Ik heb het posten van een vraag op het discussieforum vermeden omdat ik symbolen moest typen & 2.41 \\
\hline 10. & Ik zou een vraag liever persoonlijk via email stellen dan deze op het publiek discussieforum te plaatsen & 2.56 \\
\hline 11. & Ik vond het moeilijk om de antwoorden op het discussieforum te volgen. & 2.85 \\
\hline 12. & Ik deed mee aan de oefeningen in reeks: ... (nummer oefeningensessies invullen) & \\
\hline \multirow[t]{2}{*}{13.} & Bij het oplossen van de oefeningen tijdens de oefeningensessies werden wij door de assistenten & \\
\hline & goed begeleid & 3.87 \\
\hline 14. & De oplossingen van de oefeningen waren goed uitgewerkt & 3.84 \\
\hline 15. & Ik kon met mijn vragen niet bij het monitoraat terecht omdat dit reeds volzet was & 3.32 \\
\hline 16. & Ik had nood aan meer groepssessies door de monitor gegeven & 2.98 \\
\hline 17. & Ik zou liever met enkele studenten (tot een zestal) samen naar het monitoraat gegaan zijn & 2.98 \\
\hline \multirow[t]{2}{*}{18.} & Tijdens het synthesecollege beantwoordde de docent vragen die studenten op het forum & \\
\hline & hadden gesteld maar daar niet behandeld waren & 3.68 \\
\hline \multirow[t]{2}{*}{19.} & Tijdens het synthesecollege gaf de docent naast de oplossing ook feedback over de taken & \\
\hline & die hij tijdens het introductiecollege had gegeven & 3.81 \\
\hline 20. & Het grote aantal studenten heeft mij belemmerd om de colleges goed te kunnen volgen & 2.96 \\
\hline 21. & Ik vind het goed dat er punten toegekend worden aan de toetsen & 5.14 \\
\hline 22. & Ik vind het goed dat er punten toegekend worden aan medewerking aan de taken & 5.17 \\
\hline \multirow[t]{2}{*}{23.} & Ik ben het ermee eens dat uiteindelijk de student beslist of de oefeningentoetsen meetellen & \\
\hline & bij het examen of niet & 5.52 \\
\hline 24. & Het proefexamen over de theorie moet naast de toetsen blijven bestaan & 4.56 \\
\hline \multirow[t]{2}{*}{25.} & Ik zou meer gewerkt hebben voor de andere vakken als dit systeem van taken en toetsen & \\
\hline & voor biofysica niet zou bestaan hebben & 3.38 \\
\hline 26. & Ik hield in het eerste semester te weinig vrije tijd over voor ontspanning en recuperatie & 2.90 \\
\hline 27. & Vóór de kerstvakantie heb ik ongeveer ... uren per week gewerkt aan biofysica & \\
\hline 28. & Tijdens kerstvakantie en blokperiode heb ik ongeveer ... uren per week gewerkt aan biofysica & \\
\hline 29. & Docent, assistenten en monitor hebben correct verteld wat ik op het examen kon verwachten & 4.54 \\
\hline 30 & Door de combinatie van onderwijsleeractiviteiten was ik goed voorbereid op het examen & 4.38 \\
\hline \multirow[t]{2}{*}{31.} & Ondanks de voorbeelden van theorievragen op het elektronisch leerplatform, had ik er & \\
\hline & nog geen goed idee van hoe de theorie zou bevraagd worden & 2.50 \\
\hline \multirow[t]{2}{*}{32.} & Ik vond de oefeningen tijdens het examen moeilijker dan deze van de voorbereidende & \\
\hline & taken of van de oefeningenzittingen & 2.60 \\
\hline 33. & Ik had graag meer vragen over de theorie gehad & 3.03 \\
\hline 34. & Ik heb bij het examen voldoende tijd gekregen & 5.48 \\
\hline 35. & Ik ben tevreden over de onderwijsaanpak (introductiecollege - oefeningensessie - synthesecollege) & 4.92 \\
\hline
\end{tabular}

$* 1=$ helemaal niet akkoord; $2=$ niet akkoord; $3=$ eerder niet akkoord; $4=$ eerder akkoord; $5=$ akkoord; $6=$ helemaal akkoord.

opleidingsonderdeel afgerond is, zijn ze duidelijk meer tevreden dan bij de tussentijdse evaluaties (gemiddelden van 4.27 à 4.41).
Enerzijds stelt de docent enkele positieve veranderingen vast in het gedrag van de studenten: de oefeningensessies verliepen vlotter en de examenuitslagen waren hoger. Anderzijds is de aanpak tijdrovend voor de 


\section{Gemiddelde uitslag}

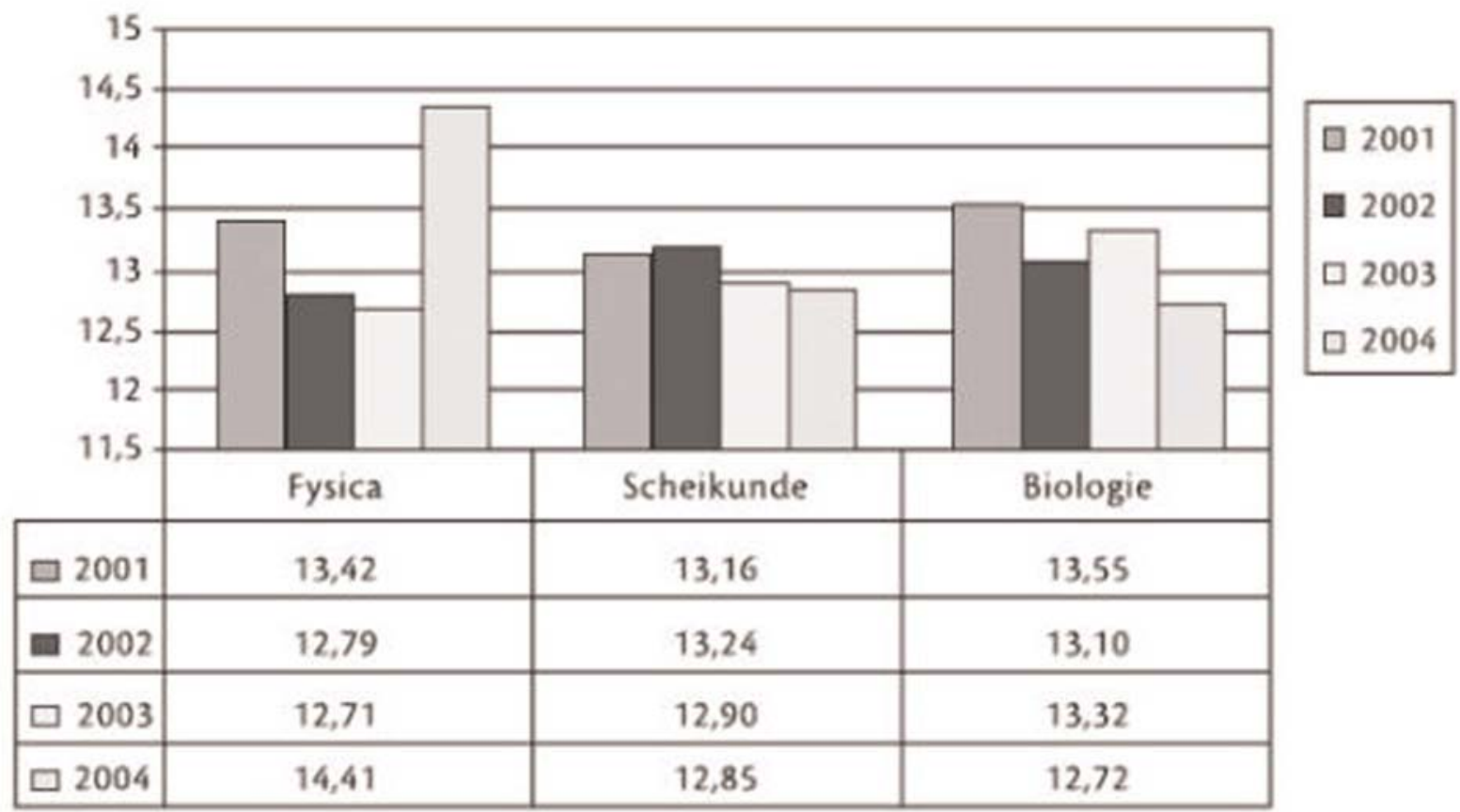

Figuur 1 De gemiddelde examenuitslag op fysica, scheikunde en biologie in de academiejaren 2001-2005.

\section{Aantal met onvoldoende}

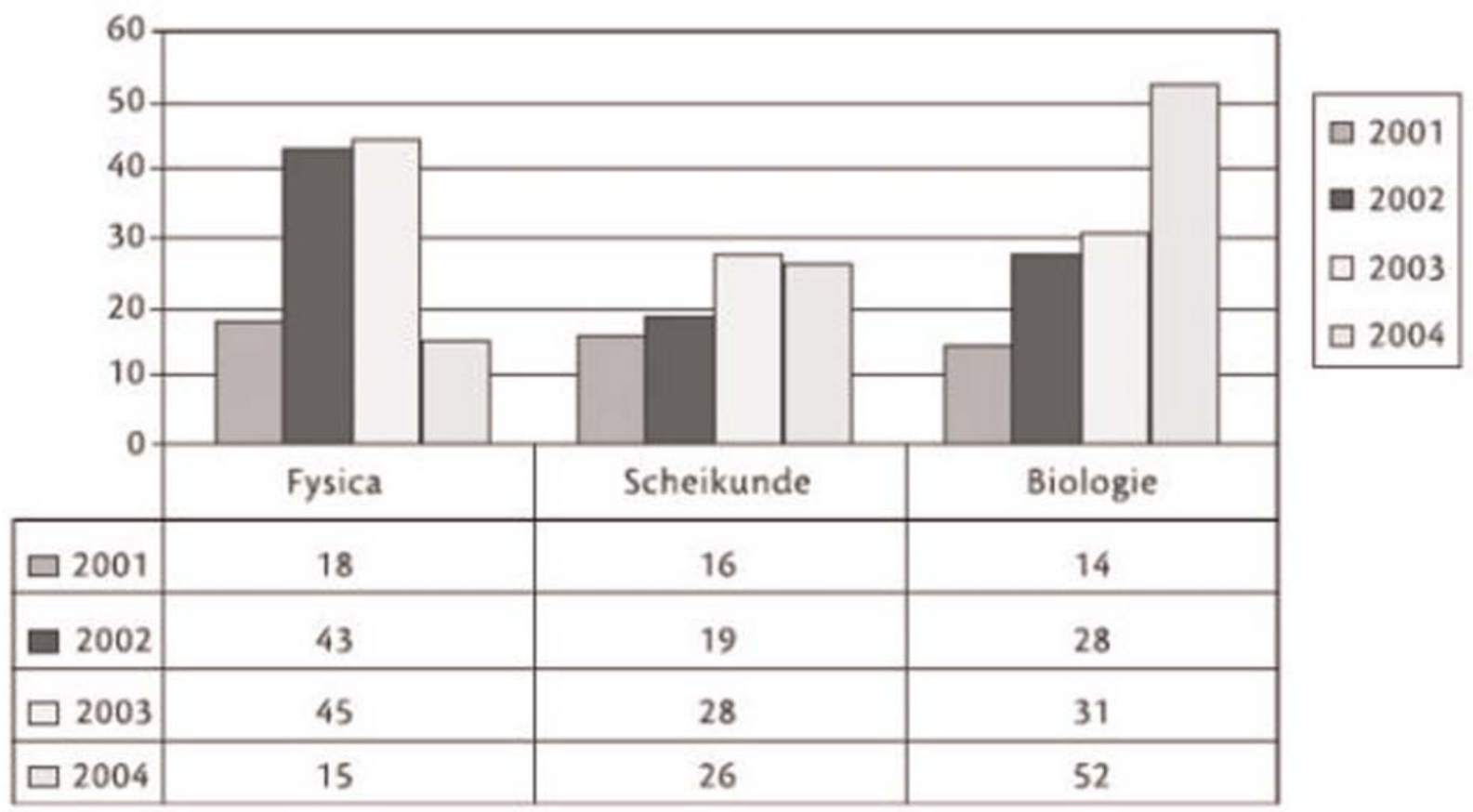

Figuur 2 Het aantal studenten met een onvoldoende op het examen van fysica, scheikunde en biologie in de academiejaren 2001-2005. 
docent: het klaarmaken van de informatie en het bijhouden van het discussieforum. Hij neemt zich voor enkele minder belangrijke aspecten van de aanpak te verbeteren. Een positieve reactie van studenten en docent op een mengeling van elektronisch met contactonderwijs werd ook in andere studies vastgesteld. ${ }^{3-4}$

De onderwijsinnovatie gaat gepaard met een sterke stijging van de gemiddelde examenuitslag voor biofysica en een sterke daling van het aantal studenten met een onvoldoende. Er kan niet met stelligheid beweerd worden dat de onderwijshervorming in biofysica negatieve repercussies had op de examenuitslag van de andere vakken, maar er moet wel over gewaakt worden dat deze, en met name biologie, niet in het gedrang komen. In enkele andere onderzoeken ging de introductie van blended learning eveneens gepaard met een significant hogere score op een examen of meerkeuzetoets. ${ }^{4-5}$

Aangezien het hoger onderwijs nu reeds bestaat uit een mengeling van elektronisch en contactonderwijs - al dan niet goed op elkaar afgestemd - is het verbijsterend dat er in het medisch onderwijs zo weinig onderzoek gebeurt rond blended learning. Elke beschrijving van een concrete uitwerking van blended learning waarbij - zoals in deze publicatie - de doeltreffendheid daarvan geobjectiveerd wordt, is bijgevolg welkom.

\section{Conclusie}

Zowel studenten als docent reageerden gunstig op de integratie van de elektronische met de fysieke leeromgeving. Deze innovatie resulteerde in een betere examenuitslag. Er moet wel over gewaakt worden dat de andere vakken niet in het gedrang komen. Dit geslaagde pilotproject is ondertussen gepresenteerd aan andere docenten als een goed voorbeeld hoe door middel van een elektronische leeromgeving de zelfwerkzaamheid van de studenten te bevorderen.

\footnotetext{
Summary

Introduction: Blended learning is aimed at integrating electronic and physical learning environments. Although much used in
}

medical education, blended leaning is seldom evaluated. A pilot project was conducted in 2004-2005 to evaluate the use of blended learning in the biophysics course in the first year of a bachelor programme in medicine and dentistry. The perceptions of the students and the trainer were studied as well as the effects on the results of the tests of three courses taught in the same semester.

Method: After each test the students completed a 19 item questionnaire and after the final test they filled out a questionnaire consisting of 32 more detailed questions. All items consisted of statements to be judged on a six-point scale. The trainer was interviewed. The results of all the tests were compared with those of the tests

on the same topics in the three preceding years.

Results: Over $80 \%$ of the total of 304 students completed all the questionnaires. The overall perceptions of the students and the trainer were positive and concerned most aspects of the innovation. The differences between the test results in the four years that were compared were only significant for biophysics. The mean test result in the year when the innovation was introduced was significantly higher than those in the three preceding years.

Discussion and conclusion: The integration of the electronic and physical learning environment was perceived favourably by the students and the teacher and resulted in higher test results. (Beullens J, Rogiers J, Volkaert L, Struyf E. An evaluation of a pilot project of blended learning in a biophysics course. Dutch Journal of Medical Education 2007;26(2):82-90.)

\section{Literatuur}

Ruiz JG, Mintzer MJ, Leipzig RM. The impact of e-learning in medical education. Acad Med 2006; 81:207-12.

Harden RM, Hart IR. An international virtual medical school (IVIMEDS): the future for medical education? Med Teach 2002;24:261-7.

Shaffer K, Small JE. Blended learning in medical education: use of an integrated approach with web-based small group modules and didactic instruction for teaching radiologic anatomy. Acad Radiol 2004;11:1059-70.

Taradi SK, Taradi M, Radic K, Pokrajac N. Blended problembased learning with Web technology positively impacts student learning outcomes in acidbase physiology. Adv Physiol Educ 2005;29:35-9.

Gordon DL, Issenberg SB, Gordon MS, Lacombe D, McGaghie WC, Petrusa ER. Stroke training of prehospital providers: an example of simulationenhanced blended learning and evaluation. Med Teach 2005;27:114-21. 